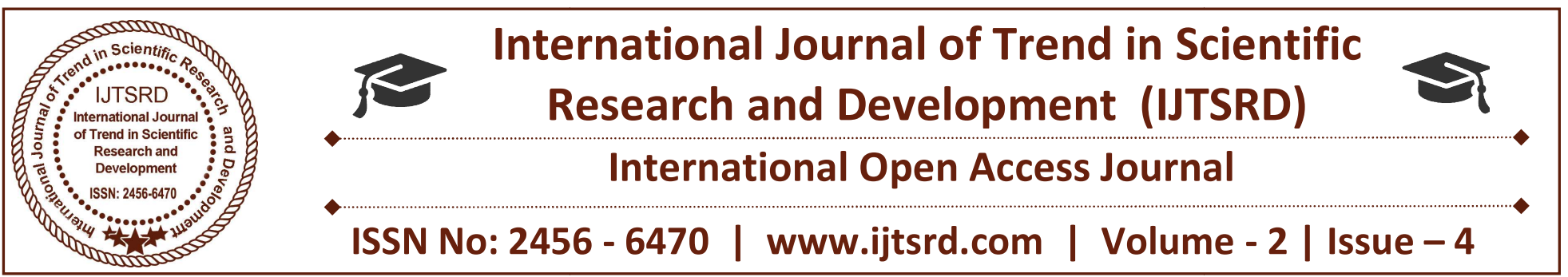

\title{
Protein Energy Wasting in CKD Patients
}

\author{
Neha Jain \\ Department of Organization \\ Pt. J. N. M. Medical College, Raipur Chhattisgarh, India
}

\section{ABSTRACT;}

A study was conducted to assess the nutritional status of CKD patients visiting Dr. B. R. A. Memorial hospital \& Pt. J. N. M. medical College Raipur (c.g.) .A total of 50 subject from both sexes having means age 49.61+_15.28 years undergoing hem dialysis were enrolled for the study. Information regarding disease history and associates co morbidities were collected from patients files. nutritional status was assessed by anthropometric measurements using body mass index (BMI).the biochemical results including kidney profile, serum electrolytes and hemoglobin were recorded from the patient's file. Dietary data was obtained by using 24- hour dietary recall and food frequency questionnaire. the results indicated that age, familial predisposition, hypertension, diabetes and heart disease increased the risk for renal failure. Protein-energy wasting (PEW) is common in patients with chronic kidney disease (CKD). PEW is one of the strongest predictors of mortality in patients with CKD. The International Society of Renal Nutrition and Metabolism (ISRNM) expert panel has defined PEW as a, "state of decreased body stores of protein and energy fuels (body protein and fat masses)". The ISRNM panel has also proposed diagnostic criteria of PEW with four categories. Cachexia is a severe form of PEW. The proposed causes of PEW are multifactorial and include nutritional and non-nutritional mechanisms. The literature indicates that PEW can be mitigated or corrected with an appropriate diet and enteral nutritional support that targets dietary protein intake. Dietary requirements and enteral nutritional support must also be considered in patients with CKD and diabetes mellitus and in children with CKD, in addition to dialysis patients. Features of ideal dietary supplement have also been discussed. Dietary interventions such as enteral feeding with high-protein meals or supplements might improve the nutritional status and outcomes in dialysis patients.

Keywords: Chronic kidney disease, nutritional intervention, protein energy malnutrition, protein energy wasting

\section{INTRODUCTION}

Management of the nutritional aspects of chronic kidney disease (CKD) presents a number of challenges. In the general population, over nutrition is a major problem. Over nutrition is considered a serious risk factor for developing metabolic syndrome, cardiovascular disease, and CKD, with a subsequent increase in the risk of mortality. However, in patients with $\mathrm{CKD}$, and especially in those undergoing maintenance dialysis, the so-called uremic malnutrition (also referred to as protein-energy wasting $[\mathrm{PEW}]$ ) is by far the strongest risk factor for adverse outcomes and death.[1] Patients undergoing dialysis die of the short-term consequences of PEW and do not live long enough to die of risk factors associated with over nutrition. This 'time discrepancy hypothesis' [2] suggests that, in a patient with CKD, whose risk of short-term mortality is high, interventions that improve nutritional status and prevent or correct wasting and sarcopenia have the potential to save lives, as compared to the conventional interventions, such as, treating hypercholesterolemia, hypertension or obesity. Furthermore, studies related to the nutritional status have shown that malnutrition / wasting is common in CKD, as approximately $18-75 \%$ of patients with CKD, undergoing maintenance dialysis therapy, show evidence of wasting. 
One recently published 10 -year cohort study evaluated serum albumin, C-reactive protein, and carotid atherosclerosis as predictors of a 10 -year mortality in hemodialysis patients. The results indicated that serum albumin concentration was far superior as a predictor of mortality than inflammatory markers (Creactive protein) or the intima-media thickness of the common carotid artery.[5] PEW, therefore, seemed to be a strong predictor of mortality in patients with $\mathrm{CKD}$, and improving nutritional status by dietary and non-dietary interventions could be an important step toward improving the outcomes in CKD

\section{NOMENCLATURE OF MALNUTRITION / WASTING SYNDROMES IN CHRONIC KIDNEY DISEASE}

Various different terms and definitions have been used by different authors for conditions associated with loss of muscle and fat tissue, malnutrition, and inflammation in patients with CKD. These include uremic malnutrition, uremic (renal) cachexia, proteinenergy malnutrition, malnutrition-inflammation atherosclerosis syndrome or malnutritioninflammation complex (or cachexia) syndrome. Use of non-uniform and ill-defined terminologies may lead to both conceptual errors and misinterpretation of data. Hence, to avoid confusion the International Society of Renal Nutrition and Metabolism (ISRNM)'s expert panel has recommended the term 'protein-energy wasting

\section{PROTEIN-ENERGY WASTING}

The ISRNM expert panel has defined PEW to describe a "state of decreased body stores of protein and energy fuels (body protein and fat masses)". This abnormality is often associated with diminished functional capacity related to metabolic stresses.

\section{Table 1}

\begin{tabular}{|l|}
\hline Potential causes of protein-energy wasting syndrome in kidney disease \\
\hline Anorexia, acidosis, anemia \\
Endocrine disorders, vitamin D deficiency, $\uparrow$ PTH, diabetes, decreased \\
insulin / IGF signalling \\
$\uparrow$ Production of inflammatory cytokines \\
Oxidative and carbonyl stress \\
Volume overload \\
$\downarrow$ Nutrient intake, prescribed dietary restrictions \\
Nutrient loss during dialysis \\
Dialysis treatment-related factors, AV graft, dialysis membrane \\
Comorbid conditions: DM, cardiovascular disease, infection, aging \\
\hline
\end{tabular}

As protein wasting and energy wasting may occasionally occur separately from each other, the term 'protein wasting' or 'energy wasting' may be used to indicate the isolated occurrence of only one of these phenomena.

\section{CACHEXIA}

In recent times, the word 'cachexia' has been suggested as a term to denote PEW included in the setting of kidney disease.[8] The ISRNM expert panel has suggested the use of cachexia for a severe form of protein-energy wasting.[7] Cachexia refers to a very severe form of PEW, often associated with profound physiological, metabolic, psychological, and immunological disorders.[9] The difference in PEW compared to cachexia is that the latter encompasses only severe forms of metabolic depletion, whereas, PEW can refer to mild degrees of depleted protein and energy mass.

\section{KIDNEY DISEASE WASTING}

According to the ISRNM expert panel, kidney disease wasting (KDW) refers to the occurrence of protein-energy wasting in CKD or acute kidney injury (AKI), regardless of the cause. The clear majority of the ISRNM panel members prefer PEW to KDW for most circumstances. The panel believes that the term KDW is not a suitable substitute for PEW. The KDW simply implies that PEW is likely to occur in people with CKD. 


\section{PROTEIN-ENERGY WASTING IN CHRONIC KIDNEY DISEASE: \\ CLINICAL IMPLICATIONS}

Several small and large scale cohort studies have revealed that protein-energy malnutrition is associated with increased morbidity, mortality, and impaired quality of life. The potential consequences of PEW are provided in

Table 2

Potential manifestations of the protein-energy wasting syndrome in kidney disease
$\uparrow$ Mortality, $\uparrow$ hospitalization, $\downarrow$ quality of life
Survival paradoxes
Atherosclerotic cardiovascular disease, vascular calcification
$\downarrow$ Weight, $\downarrow$ BMI, $\downarrow$ body fat, sarcopenia
$\downarrow$ Albumin, transthyretin and lipids, $\uparrow$ CRP

\section{PROTEIN-ENERGY WASTING,} MORTALITY, AND ALBUMIN LEVELS

Evidence indicates that surrogates of PEW, such as, low serum levels of albumin or inadequate protein intake, correlate with mortality. Measuring the serum levels of albumin remains the simplest test that is readily available. Indeed, a low serum albumin concentration is by far the strongest predictor of poor outcomes and mortality, at least in patients on dialysis, when compared with any other risk factor, including the traditional risk factors (hypertension, hypercholesterolemia, diabetes mellitus, and obesity) and the nonconventional risk factors (measures of anemia, mineral and bone surrogates, and dialysis modality)

\section{NUTRITIONAL REQUIREMENTS IN CHRONIC KIDNEY DISEASE}

Regarding dietary protein recommendations in CKD, the current Kidney Dialysis Outcome Quality Initiative (K / DOQI) guidelines suggest a protein intake of $0.6-0.75$ grams of protein per kilogram of body weight per day $(\mathrm{g} / \mathrm{kg} / \mathrm{d})$ for patients in stages $1-4$ of CKD. In stage 5 , when the patients are receiving dialysis, increased protein intake is suggested (approx. $1.2 \mathrm{~g} / \mathrm{kg} / \mathrm{d}$ ).[16] Table 4 has mentioned selected nutritional parameter requirements for varying levels of kidney disease based on the American Dietetic Association guidelines

\section{Table 4}

\begin{tabular}{|c|c|c|c|}
\hline Nutritional Parameter & Stages $1-4 \mathrm{CKD}$ & Stage 5 Hemodialysis & Stage 5 Peritoneal Dialysis \\
\hline \multirow[t]{2}{*}{ Calories (kcal / kg / d) } & $35<60$ years & $35<60$ years & $35<60$ years \\
\hline & $30-35 \geq 60$ years & $30-35 \geq 60$ years & $\begin{array}{l}30-35 \geq 60 \text { years, include } k \text { cals from } \\
\text { dialysate }\end{array}$ \\
\hline Protein (g/ kg / d) & $0.6-0.75$ & 1.2 & $1.2-1.3$ \\
\hline Fat ( $\%$ total kcal) & \multicolumn{3}{|c|}{ For patients at risk for CVD, $<10 \%$ saturated fat, $250-300 \mathrm{mg}$ cholesterol / d } \\
\hline Sodium (mg / d) & 2000 & 2000 & 2000 \\
\hline Potassium (mg / d) & Match to laboratory values & $2000-3000$ & $3000-4000$ \\
\hline Calcium (mg / d) & 1200 & $\leq 2000$ from diet and medicines & $\leq 2000$ from diet and medicines \\
\hline Phosphorus (mg / d) & Match to laboratory values & $800-1000$ & $800-1000$ \\
\hline Fluid (mL / d) & Unrestricted with normal urine output & $1000+$ urine & Monitor; 1500 - 2000 \\
\hline
\end{tabular}

\section{IMPROVING NUTRITIONAL STATUS IN CHRONIC KIDNEY DISEASE}

Oral nutritional consideration: Intervention may begin with suggestions to enhance oral intake in malnourished CKD patients

\begin{tabular}{|l|}
\hline Strategies to enhance oral intake \\
\hline Avoid diet restrictions in patients with poor intake \\
Offer oral liquid supplements and snacks \\
Treat gastroparesis and other gastrointestinal conditions \\
Achieve glycemic control \\
Correct electrolyte abnormalities \\
Evaluate for and address depression
\end{tabular}


Materials \& Methods:-. Total 50 patients were admitted. All patients were subjected to routine blood investigations, blood glucose, urine analysis, routine biochemical investigations, sickling, lipid profile, ECG, Serum Protein, ,X Ray chest, USG(KUB), serum calcium, potassium, chloride, sodium, phosphorus, albumin, globulin, bilirubin triglyceride, HDL,LDL, VLDL,SGOT, SGPT, Hb Electrophoresis, Serum Thyroid levels.

\section{CONCLUSIONS}

Fifty years after the first dialysis treatment, nutrition is still a recurrent issue and many disorders are currently not well understood. However, there has been progress in understanding the nutritional targets in CKD patients. Before dialysis, there is good evidence that a longstanding nutritional care plan, with control of protein intake, is efficient for correcting many metabolic disorders, including proteinuria, and it is cost-effective. PEW is a distinct condition in CKD patients. PEW is common in CKD and is associated with adverse outcomes. Dietary interventions and nutritional support seem to be effective in mitigating or correcting PEW and improving the outcomes in patients with CKD. All patients with CKD should be assessed periodically (monthly or quarterly) for the presence of PEW and should be offered oral nutritional support whenever required. Providing meals or oral nutritional supplements and other nutritional interventions to patients with CKD is the most promising way to increase serum albumin concentration and improve longevity and quality of life in this patient population.

\section{REFERENCES}

1. Kovesdy CP, Kalantar-Zadeh $\mathrm{K}$. Why is protein-energy wasting associated with mortality in chronic kidney disease? Semin Nephrol. 2009; 29:3-14. [PMC free article] [Pub Med]

2. Kalantar-Zadeh K, Block G, Horwich T, Fonarow GC. Reverse epidemiology of conventional cardiovascular risk factors in patients with chronic heart failure. J Am Coll Cardiol. 2004;43:1439-44.[Pub Med]

3. Kopple JD. McCollum Award Lecture, 1996: Protein-energy malnutrition in maintenance hemodialysis patients. Am J Clin Nutr. 1996 65:1544-57. [PubMed]

4. Kalantar-Zadeh K, Ikizler TA, Block G, Avram MM, Kopple JD. Malnutrition-inflammation complex syndrome in dialysis patients: Causes and consequence. Am J Kidney Dis. 2003; 42:864-81. [Pub Med]

5. Kato A, Takita T, Furuhashi M, Maruyama Y, Hishida A. Comparison of serum albumin, Creactive protein and carotid atherosclerosis as predictors of 10-year mortality in hemodialysis patients. Hemodial Int. 2010; 14:226-32. [Pub Med]

6. Kalantar-Zadeh K, Cano NJ, Budde K, Chazot C, Kovesdy CP, Mak RH, et al. Diets and enteral supplements for improving outcomes in chronic kidney disease. Nat Rev Nephrol. 2011; 7:369-84.[PMC free article] [Pub Med]

7. Fouque D, Kalantar-Zadeh K, Kopple J, Cano N, Chauveau P, Cuppari L, et al. A proposed nomenclature and diagnostic criteria for proteinenergy wasting in acute and chronic kidney disease. Kidney Int. 2008; 73:391-8. [PubMed]

8. Kalantar-Zadeh K. Recent advances in understanding the malnutrition-inflammationcachexia syndrome in chronic kidney disease patients: What is next? Semin Dial. 2005;18:365 [Pub Med]

9. Martignoni ME, Kunze P, Friess H. Cancer cachexia. Mol Cancer. 200 3;2:36. [PMC free article][Pub Med]. 